Ergod. Th. \& Dynam. Sys. (1981), 1, 523-524

Printed in Great Britain

\title{
Index to Volume 1
}

AlPERN, S. Return times and conjugates of an antiperiodic transformation, 135

AUSLANDER, J. AND VAN DER WOUDE, J. Maximally highly proximal generators of minimal flows, 389

Bernhardt, C. Periodic orbits of continuous mappings of the circle without fixed points, 413

BESSON, O. On the entropy in $\mathrm{II}_{1}$ von Neumann algebras, 419

BLANCHARD, P. AND Franks, J. An obstruction to the existence of certain dynamics in surface diffeomorphisms, 255

Block, L., Coven, E. M. AND NITECKI, Z. Minimizing topological entropy for maps of the circle, 145

BRIN, M. Bernoulli diffeomorphisms with $n-1$ non-zero exponents, 1

CONNES, A., FELDMAN, J. AND WEISS, B. An amenable equivalence relation is generated by a single transformation, 431

Coven, E. M. AND Nitecki, Z. Non-wandering sets of the powers of maps of the interval, 9

Coven, E. M. See Block, L. et al.

DERRIENNIC, Y. AND KRENGEL, U. Subadditive mean ergodic theorems, 33

Ell.IS, R. Cohomology of groups and almost periodic extensions of minimal sets, 49

Feldman, J. See Connes, A. et al.

Franks, J. See Blanchard, P. AND Franks, J.

GLASNER, S. AND WEISS, B. A weakly mixing upside-down tower of isometric extensions, 151

HALL, G. R. A $C^{\infty}$ Denjoy counterexample, 261

HAMACHI, T. On a Bernoulli shift with non-identical factor measures, 273

HeRman, M. R. Construction d'un difféomorphisme minimal d'entropie topologique non nulle, 65 HOFBAUER, F. The structure of piecewise monotonic transformations, 159

DEL JUNCO, A. Finitary codes between one-sided Bernoulli shifts, 285

KEYNES, H. B. AND SEARS, M. Real-expansive flows and topological dimension, 179

KRENGEL, U. See DeRRIENNIC, Y. AND KRENGEL, U.

LEDRAPPIER, F. Some properties of absolutely continuous invariant measures on an interval, 77

Mañé, R. A proof of Pesin's formula, 95

MANNING, A. A relation between Lyapunov exponents, Hausdorff dimension and entropy, 451 MisiurewiCZ, M. On iterates of $e^{z}, 103$

Nitecki, Z. See Coven, E. M. And Nitecki, Z., and Block, L. et al.

PARRY, W. Self-generation of self-replicating maps of an interval, 197

PARRY, W. AND TunCEL, S. On the classification of Markov chains by finite equivalence, 303

REES, M. An alternative approach to the ergodic theory of measured foliations on surfaces, 461

REES, M. Checking ergodicity of some geodesic flows with infinite Gibbs measure, 107

REES, M. Divergence type of some subgroups of finitely generated Fuchsian groups, 209 
SCHMIDT, K. Amenability, Kazhdan's property $T$, strong ergodicity and invariant means for ergodic group actions, 223

Sears, M. See Keynes, H. B. And Sears, M.

SERIES, C. The infinite word problem and limit sets in Fuchsian groups, 337

SPATZIER, R. J. On lattices acting on boundaries of semi-simple groups, 489

THIMM, A. Integrable geodesic flows on homogeneous spaces, 495

Tuncel, S. See Parry, W. AND Tuncel, S.

Weiss, B. See Glasner, S. AND Weiss, B., and Connes, A. et al.

WrLson, G. The modified Lax and two-dimensional Toda lattice equations associated with simple Lie algebras, 361

VAN Der Woude, J. See Auslander, J. AND VAN Der Woude, J.

YouNG, L.-S. Capacity of attractors, 381

ZIMMER, R. J. Equivariant images of projective space under the action of $\operatorname{SL}(n, \mathbb{Z}), 519$

ZIMMER, R. J. Orbit equivalence and rigidity of ergodic actions of Lie groups, 237 